\title{
Sulu Çözeltiden Bakır (II) Adsorpsiyon Sürecinin Optimizasyonunda Yüzey Yanıt Metodolojisinin Uygulanması
}

\author{
Yunus Emre Şimşek \\ Bilecik Şeyh Edebali Üniversitesi, Mühendislik Fakültesi, Kimya Mühendisliği, Bilecik \\ yunusemre.simsek@bilecik.edu.tr,
}

Araştırma Makalesi

Geliş Tarihi: 12.02 .2018

Kabul Tarihi: 21.07.2018

$\ddot{O} \mathbf{z}$

Bu çalışmada sulu çözeltilerden Bakır (II) giderimi için ham Brassica Napus bitki sapları adsorban olarak kullanılmıştır. Kesikli adsorpsiyon deneylerinde sabit 120 dakikalık temas süresince, $\mathrm{pH}(2-10)$, metal çözelti derişimi (2-10 mg/L), adsorban miktarı (0.03-0.07 g), ve sıcaklık $\left(30-50{ }^{\circ} \mathrm{C}\right)$ adsorpsiyon deney değişkenleri olarak seçilmiştir. Bu dört bağımsız değişken yüzey merkezli merkezi birleşik tasarımına dayanan yüzey yanıt yöntemi kullanılarak optimize edilmiştir. Bakır (II) adsorpsiyonu için optimum koşullar $7.3 \mathrm{mg} / \mathrm{L}$ bakır (II) iyon derişimi, $5.9 \mathrm{pH}, 0.03 \mathrm{~g}$ adsorban miktarı ve $33{ }^{\circ} \mathrm{C}$ olduğu yüzey merkezli merkezi birleşik tasarım yöntemi ile bulunmuştur. Elde edilen bu optimum koşullarda, adsorbanının \%79 kadar Bakır (II) ağır metal giderimini gerçekleştirdiği deneysel yöntemlerle hesaplanmıştır. Önerilen yüzey merkezli merkezi birleşik tasarımının iyi bir doğruluk ve yüksek regresyon katsayına $\left(R^{2}=0.992\right)$ sahip en iyi istatiksel yöntem olduğu bulunmuştur. Sonuçlar açık bir biçimde Brassica Napus bitki saplarının ucuz bir adsorban olarak Bakır (II) giderimi için kullanılabileceğini göstermektedir.

Anahtar Kelimler: Adsorpsiyon, Bakır (II) giderimi,yüzey yanıt yöntemi, optimizasyon

\section{Application of Response Surface Methodology in the Optimization of Copper (II) Adsorption Process from Aqueous Solution}

\author{
Yunus Emre Şimşek \\ Bilecik Şeyh edebali University, Engineering Faculty, Department Of Chemistry \\ yunusemre.simsek@bilecik.edu.tr
}

\begin{abstract}
In this study, Brassica Napus straw was used as an adsorbent to eliminate Copper (II) from aqueous solution. In batch adsorption experiments with a fixed contact time of $120 \mathrm{~min}$, experimental variables were selected as $\mathrm{pH}(2-10)$, metal solution concentration $(2-10 \mathrm{mg} / \mathrm{L})$, adsorbent dosage $(0.03-0.07 \mathrm{~g})$, and temperature $\left(30-50{ }^{\circ} \mathrm{C}\right)$. These four independent variables were optimized using response surface methodology based on a four-independent variable face-centered central composite design. The optimum conditions for Copper (II) adsorption were found to be Copper (II) ion concentration of $7.3 \mathrm{mg} / \mathrm{L}, \mathrm{pH}$ of $5.9,0.03 \mathrm{~g}$ of adsorbent dosage, and temperature of $33^{\circ} \mathrm{C}$. At the optimized conditions, up to $79 \%$ Copper (II) heavy metal ions managed to remove from heavy metal solution onto Brassica Napus straw. The face-centered central composite design proposed turned out be the best statistical model to predict the response with good accuracy and a high regression coefficient $\left(\mathrm{R}^{2}=0.992\right)$. Results clearly suggest that Brassica Napus straw can be used for the Copper (II) adsorption as a low-cost adsorbent.
\end{abstract}

Keywords: Adsorption, Copper (II) removal, response surface methodology, optimization 


\section{GíRiş}

Endüstride giderek artan miktarlarda kadmiyum, krom, bakır, kurşun ve nikel gibi ağır metal iyonlarının kullanılması insan sağlığı ve çevre için giderek daha büyük bir tehdit oluşturmaktadır. Bakır; insanlar, bitkiler, hayvanlar ve mikroorganizmalar gibi tüm biyolojik canlılar için eser miktarlarda gerekli olan bir elementtir. Ancak eser miktarlardaki sınırın üzerindeki derişimlere maruz kalan insanlarda, karaciğer, kemik, bağışıklık sistemi bozukluklarına neden olmakta ve merkezi sinir sistemine ciddi zararlar vermektedir. Bu yüzden Bakır (II) ağır metalin endüstriyel atı sulardan ayrılması ya da derişimlerinin güvenli bir sınırın altına düşürülmesi biyolojik canlılar için temel bir zorunluluktur. Bakır yüzey suyu, yer altı suyu, deniz suyu ve içme sularında bakır komplekleri yada askıda katı madde olarak bulunmaktadır. Amerika Birleşik Devletleri Çevre Koruma Ajansı (EPA) Güvenli İçilebilir Su Maddesine göre içilebilir sulardaki bakır derişimi maksimum $1.3 \mathrm{mg} / \mathrm{L}$ olarak belirlenmiştir [1].

Ters ozmos, sıvı-sıvı özütleme, iyon değişim, bulut noktası özütleme, elektrokimyasal biriktirme, adsorpsiyon, membran süreçleri, koagülasyon-flokülasyon ve elektrokimyasal oksidazyon gibi bazı teknikler yardımıyla atık sulardan ağır metal giderimi yapılmaktadır [2-6]. Sözü edilen bu süreçler içersinde endüstriyel ölçekte ağır metal giderimi için en sık kullanılan yöntem adsorpsiyondur. Ancak adsorpsiyon süreçlerinde adsorban olarak sıklıkla kullanılan aktif karbonun maliyeti yüksek olup, adsorbanın rejenerasyon maliyeti tüm sürecinin maliyetini yükseltmektedir. $\mathrm{Bu}$ yüzden son yıllarda yüksek adsorpsiyon kapasitesine sahip düşük maliyetli tarımsal katı atıklar [7-8], bioadsorbanlar [9], gida atıkları [10] ve killer [11] gibi alternatif adsorbanlardan yararlanılarak ağır metal gideriminde kullanılmasına ilişkin çalışmalara hız verilmiştir. Adsorpsiyon kapasitesini etkileyen faktörler;adsorban yüzey doku ve morfolojik özellikleri, adsorban yüzey fonksiyonel grupları, adsorban miktarı, ağır metal derişimi, sıcaklık ve pH'dır. Adsorpsiyonu etkileyen bu çok sayıda faktörün optimizasyonu ile adsorpsiyon süreci daha iyi anlaşılabilmektedir.

Yüzey Yanıt Yöntemi endüstriyel süreçleri ve bu süreçlerden elde edilen ürünlerin geliştirilmesinde, iyileştirilmesinde ve optimizasyonunda kullanılan matematiksel ve istatiksel araçtır. Belli bir sürecin üretimini, ürün verimini ya da istenilmeyen ürün miktarını pek çok aktör etkiliyorsa bu süreçte Yüzey Yanıt Yönteminin kullanımı sürecin doğru bir biçimde çözümlenmesini sağlamaktadır. Deney tasarımı ile başlayan Yüzey Yanıt Yöntemi bir süreci ya da deneyi etkileyen önemli faktörleri belirlemek için kullanılır. Yüzey Yanıt Yöntemi ile üretilen veriler aracılığıyla ürünü maksimize ederken deney sayısını azaltmayı hedefler. Veriler, yanıt (response) ile deneysel faktörler arasında ilişki kuran ampirik modelleri geliştirmek için de kullanılabilir. $\mathrm{Bu}$ modeller deneyler ile doğrulanan daha iyi bir süreç yanıtını araştırmayı kolaylaştırmaktadır. Modeller optimal süreç belirlenene kadar uygun model denenerek iteratif yöntem ile en uygun modele ulaşmaya çalışır. Simetrik deneysel tasarım türleri üç seviyeli faktöriyel tasarım, merkezi birleşik tasarım, Doehlert ve Box-Behnken gibi yöntemlerini kapsamaktadır [3,6].

Tarım sektörü Türkiye ekonomisinde önemli bir rol oynamaktadır. Son on yilda sanayi ve hizmet sektörlerindeki artışa rağmen Türkiye nüfusunun neredeyse \%30'u tarım sektöründe istihdam edilmektedir. Türkiye'de ekilen tarım arazisi yaklaşı 22 milyon hektar olup 2016 y1l itibariyle 10683 hektarda kanola (Brassica napus) bitkisinin tarımı yapılmakta ve 1250000 ton kanola bitki sap1 olarak sap ve daneli ürün elde edilmektedir. Brassica Napus bitkisi yüksek yağ miktarı ile hem gıda ve hem de biyodizel üretim piyasalarında oldukça talep görmektedir. Diğer yağlı bitkiler (ay çiçeği ve mısır gibi) ve baklagil ürünleri ile karşılaştırıldığında üretim masrafları oldukça düşüktür [12]. Bu çalışmada hasat sonrası elde kalan ve hiç bir ekonomik değeri olmayan Brassica Napus bitki saplarının düşük maliyette Bakır (II) giderimi için etkili bir adsorban potansiyeline sahip olup olamayacağ 1 araştırılmıştır. Adsorpsiyon süreci değişkenleri olarak, adsorban miktarı, $\mathrm{pH}$, ilk derişim ve sıcaklık seçilmiş, Yüzey Yanıt Yöntemi ile süreç optimize edilmiştir. Ayrıca adsorpsiyon öncesi ve sonrası adsorban FTIR, SEM-EDX ve XRD ile karakterize edilmiştir.

\section{MALZEME VE YÖNTEM}

\subsection{Ham materyal}

Deneylerde adsorban olarak kullanılan Brassica Napus bitkisi sapları 2016 yılında Bilecik ili Gökpınar köyünde 2016 yılı hasat sonrası kalan bitki sapı atıklarıdır. Tarlada toplanan bu atıklar ilk olarak 30 gün boyunca açık havada ve güneş görmeyen bir ortamda kurutulmuştur. Adsorpsiyon deneyleri öncesi bu saplar değirmende öğütülmüş ve elekten geçirilerek uygun partikül boyutunda $(0.112 \pm 0.004 \mathrm{~mm})$ deneylere hazır hale getirilmiştir. Deneyler öncesinde dış ortamdan gelen kirleticilerin ve safsızlıkların uzaklaştırılması için tüm numune saf sudan 
geçirilmiş ve etüvde $100{ }^{\circ} \mathrm{C}$ 'de iki gün boyunca sonuçları Tablo 1'de verilmiştir.

kurutulmuştur. Ham materyalin kaba ve elementel analiz

Tablo 1. Brassica Napus bitki saplarının kaba ve elementel analiz sonuçları

\begin{tabular}{lllll}
\hline Kaba analiz & Ağırlıça \% & Uygulanan standart & Elementel analiz & Ağırlıça \% \\
\hline Uçucu madde & 73.91 & E $897-88$ & Karbon & 42.59 \\
Sabit karbon ${ }^{\mathrm{a}}$ & 13.24 & - & Hidrojen & 7.21 \\
Kül & 4.90 & D $1102-84$ & Azot & 0.88 \\
Nem & 7.95 & D 2016-74 & Oksijen & 49.32 \\
\hline
\end{tabular}

${ }^{\mathrm{a}}$ Farktan

\subsection{Ağır metal çözeltisinin hazırlanması}

Deneylerde ağır metal stok çözeltisi hazırlamak için kullanılan Bakır (II) nitrat trihidrat $\left(\mathrm{Cu}\left(\mathrm{NO}_{3}\right) 2.3 \mathrm{H}_{2} \mathrm{O}\right.$, Merck CAS No:10031-43-3) kullanılmıştır. Bu kimyasaldan deneylerde kullanılmak üzere uygun miktarlarda ultra saf su ile ağır metal çözeltileri hazırlanmış ve adsorpsiyon sonucu bakır (II) derişimi UV-Vis (Agilent Cary 60 Spectrophotometer) ile $580 \mathrm{~nm}$ dalga boyunda okumalar yapılarak hesaplanmıştır.

\subsection{Kesikli reaktörde adsorpsiyon deneyleri}

Bakır (II) giderimi deneyleri yüzey merkezli birleşik tasarımına göre süreç parametrelerini değiştirilerek yürütülmüştür. Deneylerde kullanılmak üzere arzu edilen derişimlerde (2-10 mg/L) bakır (II) ağır metal çözeltisi hazırlamak için, bakır (II) nitrat stok çözeltisi (1000 mg/L) hazırlanmış ve her deney öncesi istenilen derişimler bu stok çözeltisinden ultra saf su ile seyreltilerek hazırlanmıştır. İstenilen $\mathrm{pH}(2-10) 0.1 \mathrm{M} \mathrm{NaOH}$ ve $0.1 \mathrm{M} \mathrm{HCl}$ çözeltileri ile ayarlanmıştır. Adsorpsiyon deneyleri kesikli çoklu manyetik karıştırıcıda (Dlab MS-H-S10 10 Channel Classic Hot Plate Magnetic Stirrer) ve farklı sicaklılarda (30-50 $\left.{ }^{\circ} \mathrm{C}\right)$ gerçekleştirilmiştir. Farklı miktarlarda adsorban (0.03-0.07 g) $50 \mathrm{~mL}$ hacmindeki ağır metal çözeltisine eklenmiş, belirli sicaklık ve pH'larda 150 dakika boyunca ve $250 \mathrm{rpm}$ dönüş hızında adsorpsiyon işlemi gerçekleştirilmiştir. Ağır metal giderimi ve adsorpsiyon kapasitesi $580 \mathrm{~nm}$ dalga boyunda UV-Vis Spektrofotometre cihazı kullanılarak okumalar yapılmış ve aşağıdaki formüller ile hesaplanmıştır.

$\operatorname{Giderim}(\%)=\frac{C_{0}-C_{t}}{C_{0}} \times 100$
Adsorpsiyon kapasitesi, $q\left(\frac{m g}{g}\right)=\frac{C_{0}-C_{t}}{W} \times V(2)$

Burada $C_{0}(\mathrm{mg} / \mathrm{L})$ ve $C_{t}(\mathrm{mg} / \mathrm{L})$ sirasıyla başlangıç ve 150 dakika sonraki sıvı faz derişimlerini, V (L) çözelti hacmini ve W (g) kullanılan adsorbanın kütlesini göstermektedir.

\subsection{Adsorban karakterizasyonu}

\section{Yüzey morfolojisi ve elementel analiz}

Adsorban olarak kullanılan Brassica Napus bitkisi sap1 atıklarının yüzey dokusu ve morfolojisi analizi SEM ZeissSupra 40Vp Gemini ile gerçekleştirilmiştir. Ham maddenin sahip olduğu $\mathrm{C}, \mathrm{H}, \mathrm{N}$ ve $\mathrm{O}$ içeriği LECO CHN 628 Analyzer ile belirlenmiştir.

\section{Fourier Transform Infrared Spektroskopisi (FTIR)}

Fourier Transform Infrared Spektroskopisi (FTIR) adsorbanda var olan fonksiyonel grupların belirlenmesi amacıyla kullanılmıştır. Bakır (II) adsorpsiyonu öncesinde ve sonrasındaki adsorbanların spektrumları Agilent Cary 630 FTIR Spectrometer kullanılarak kaydedilmiştir. Adsorbana ait olan spektrumlar $2.0 \mathrm{~cm}^{-1}$ çözünürlüğünde $500-4000 \mathrm{~cm}^{-1}$ dalga boyu aralığında geçirgenlik modunda alınmıştır.

\subsubsection{Işını Kırınım Difraktometresi (XRD)}

Bakır (II) adsorpsiyonu öncesi ve sonrası yüzey kompleks gruplarının belirlenmesi amacıyla $X \quad$ ışını kırınım difraktometresi kullanılmıştır. Yüzey kompleks grup analizi $1 \%$ dakika gonyometre tarama hızında ve $2 \theta$ tarama açısında $5^{\circ}$ ile $90^{\circ}$ aralığında PANanalytical X'pert HT-XRD cihazı kullanılarak XRD analizleri gerçekleştirilmiştir. 


\subsection{Deney tasarımı ve optimizasyon}

Bu çalışmada kesikli (batch) sistem adsorpsiyon deneylerini etkileyen faktörlerin etkisini anlamak ve uygun modeli oluşturmak için MATLAB $®$ Mathworks (v.2013) yazılımı kullanılmıştır. Adsorpsiyon sürecini etkileyen değişkenler olarak pH, $\mathrm{X}_{1}$ (2-10), ilk derişim, $\mathrm{X}_{2}(2-10 \mathrm{mg} / \mathrm{L})$, adsorban miktarı $\mathrm{X}_{3}(0.03-0.07 \mathrm{~g} / \mathrm{L})$ ve sicaklık, $\mathrm{X}_{4}\left(30-50{ }^{\circ} \mathrm{C}\right)$ seçilmiştir.

Adsorban miktarl $Y, q\left(\frac{m g}{g}\right)=\beta_{0}+\beta_{1} X_{1}+\beta_{2} X_{2}+\beta_{3} X_{3}+\beta_{4} X_{4}+\beta_{12} X_{1} X_{2}+\beta_{13} X_{1} X_{3}+\beta_{14} X_{1} X_{4}+\beta_{23} X_{2} X_{3}+$ $\beta_{24} X_{2} X_{4}+\beta_{34} X_{3} X_{4}+\beta_{11} X_{1}^{2}+\beta_{22} X_{21}^{2}+\beta_{33} X_{3}^{2}+$ $\beta_{44} X_{4}^{2}$

Yüzey merkezli birleşik tasarıma göre, $2^{4}$ faktöriyel nokta, 4 küp merkez nokta, 8 eksenel nokta ve 2 eksende merkez nokta olmak üzere toplam 30 deney gerçekleştirilmiştir. Yanıt ve bağımsız değişkenler arasındaki ilişki ikinci dereceden etkileşimli Eşitlik 3 yardımıyla modellendirilmiştir.

Burada $Y$ tahmin edilen yanıt iken $X_{1}, X_{2}, X_{3}$ ve $X_{4}$ bağımsız değişkenlerin kodlanmış biçimidir. $\beta_{0}$ sabit katsayı olup, $\beta_{1}, \beta_{2}, \beta_{3}$,ve $\beta_{4}$ doğrusal katsayılar; $\beta_{11}$, $\beta_{22}, \beta_{33}$,ve $\beta_{44}$ karesel katsay1lar ve $\beta_{12}, \beta_{13}, \beta_{14}, \beta_{23}, \beta_{24}$ ve $\beta_{34}$ etkileşim katsayılarıdır. Model uydurma adımları, veri analizi ve denklemdeki istatiksel önemin değerlendirilmesi için MATLAB® (v.13, Nonlinear Optimization Toolbox) yazılımı kullanılmıştır. Eşitlik 3'deki bağımsız değişkenlerin uygunluğu varyans analizi (ANOVA) ile değerlendirilmiştir.

\section{BULGULAR VE TARTIŞMA}

\subsection{Süreç modelinin uygunluğu ve istatiksel analiz}

Yüzey yanıt yöntemi ile tasarlanan 30 deneyin incelenmesi $\mathrm{pH}\left(\mathrm{X}_{1}\right)$, ilk derişim $\left(\mathrm{X}_{2}\right)$, adsorban miktarı $\left(\mathrm{X}_{3}\right)$ ve sıcaklık $\left(\mathrm{X}_{4}\right)$ bağımsız değişkenlerin adsorban kapasitesi (Y) etkisini incelemek için yapılmıştır. Her bir deneysel koşula karşılık gelen ağır metal bakır (II) giderimine ilişkin kodlu ve kodsuz yüzey merkezli birleşik tasarım tablosu ve adsorban kapasitesi sonuçları Tablo 2'de verilmiştir.

Adsorban miktarl, $q\left(\frac{m g}{g}\right)=1.4186+0.4160 X_{1}+2.1851 X_{2}-229.130 X_{3}+0.0779 X_{4}-0.0198 X_{1} X_{2}+3.7798 X_{1} X_{3}-$ $0.0052 X_{1} X_{4}-18.1355 X_{2} X_{3}-0.0051 X_{2} X_{4}-0.1218 X_{3} X_{4}-0.0234 X_{1}^{2}+0.0026 X_{2}^{2}+2152.58 X_{3}^{2}-6.9213 E-05 X_{4}^{2}$

Deneysel sonuçları optimize etmek için, Yüzey yanıt yöntemi kullanılmış ve deneysel koşullara ve sonuçlara en uygun model belirlenmiştir. Çoklu regresyon analizi kullanılarak adsorban miktarını (Yanıt (Y), q) bağımsız değişkenlere bağlayan ifade Eşitlik 4'de verilmiştir.

$\mathrm{Bu}$ eşitlikte (q) adsorplanan miktarı olup, $\mathrm{X}_{1}, \mathrm{X}_{2}, \mathrm{X}_{3}$ ve $\mathrm{X}_{4}$ sırasıyla $\mathrm{pH}$, ilk derişim, adsorban miktarı ve sıcaklıktır. Bakır (II) adsorpsiyonu için yanıt yüzey yöntemi ile elde edilen varyans analiz (ANOVA) değerleri Tablo 3'de gösterilmiştir.

Modelde var olan katsayıların önemi $\mathrm{F}$ ve $\mathrm{P}$ değerlerinden belirlenmiştir. Varyans analizinin (ANOVA) uygulanması modelin uygunluğunu belirlemede ve değerlendirmede en güvenilir yöntem olduğu bilinmektedir [1-2,4]. Düşük $P$ değerlerine $(<0.05)$ sahip $F$ değeri (129.651) regresyon modelinin istatiksel olarak önemli olduğunu göstermektedir. F değerleri artıkça ve P değerleri düştükçe ikinci dereceden etkileşimli modelin daha yüksek istatiksel öneme sahip olduğu görünmektedir. Ayrıca yüksek regresyon katsayısı $\left(\mathrm{R}^{2}=0.9593\right)$ önerilen modele çok yakın bir sonuca ulaşıldığını göstermektedir. ANOVA tablosundan açıkça görüldüğü gibi $X_{1}, X_{2}, X_{3}$ ve $X_{4}$ adsorban üzerinde bakır (II) gideriminde önemli belirgin bazı etkilere sahip olduğu görünmektedir. Birinci dereceden doğrusal olarak $\left(\mathrm{X}_{1}, \mathrm{X}_{2}\right.$ ve $\left.\mathrm{X}_{3}, \mathrm{P}<0.05\right)$, ikinci dereceden etkileşimli $\left(X_{2}\right.$ ve $\left.X_{3}, P \quad<0.05\right)$ ve ikinci dereceden etkileşimsiz (saf ikinci dereceden, $\mathrm{X}_{3}, \mathrm{P}<0.05$ ) adsorpsiyon deneylerinde çok önemli değişkenler olduğu Tablo 3'den açıkça görünmektedir. Faktörlerin geri kalanlarının $P$ değerleri 0.05 değerinden daha yüksek olduğundan modelde daha az önemli oldukları düşünülebilir. Önerilen ikinci dereceden etkileşimli modelin uygunluğu model uyumsuzluğu (lack-of-fit) verilerinden belirlenebilir. Bu verilere dayanarak önerilen modele dayanan veriler ile deneysel verilerin karşılaştırılması Şekil 1'de verilmiştir.

Şekil 1'den de görülebileceği gibi deneyler sonucu elde edilen veriler ile bu çalışmada önerilen ve Eşitlik 4 ile gösterilen modelden elde edilen veriler yüksek bir regresyon katsayısı ile uyum içersindedir. Ayrıca adsorban kapasitesi pH (2-10), ilk derişim (2-10 ppm), adsorban miktarı $(\mathrm{g})$ ve sıcaklık $\left(30-50{ }^{\circ} \mathrm{C}\right)$ sınırlayıcı değişkenler aracılığıyla maksimize edilmiştir. Maksimizasyon sonuçları Tablo 4'de verilmiştir. 
Tablo 2. Deneysel tasarım ve yüzey yanıt tasarımının sonuçları

\begin{tabular}{|c|c|c|c|c|c|c|c|c|c|}
\hline \multirow{3}{*}{ Deney sirası } & \multicolumn{7}{|c|}{ Bağımsız değişkenler } & & \multirow{3}{*}{$\begin{array}{l}\text { Yanit } \\
\text { Adsorban } \\
\text { kapasitesi } \\
(\mathrm{mg} / \mathrm{g})(\mathrm{q})\end{array}$} \\
\hline & \multicolumn{5}{|l|}{$\mathrm{X}_{1}$} & \multicolumn{3}{|c|}{$\begin{array}{l}\text { Sicaklik } \\
\mathrm{X}_{4}\left({ }^{\circ} \mathrm{C}\right)\end{array}$} & \\
\hline & Kodsuz & Kodlu & Kodsuz & Kodlu & Kodsuz & Kodlu & Kodsuz & Kodlu & \\
\hline 1 & 8 & 1 & 8 & 1 & 0.04 & -1 & 45 & 2 & 8.41 \\
\hline 2 & 6 & 0 & 6 & 0 & 0.05 & 0 & 50 & 2 & 5.44 \\
\hline 3 & 8 & 1 & 4 & -1 & 0.04 & -1 & 45 & 1 & 4.39 \\
\hline 4 & 6 & 0 & 6 & 0 & 0.05 & 0 & 30 & -2 & 5.52 \\
\hline 5 & 6 & 0 & 6 & 0 & 0.05 & 0 & 40 & 0 & 5.02 \\
\hline 6 & 8 & 1 & 4 & -1 & 0.04 & -1 & 30 & -2 & 4.13 \\
\hline 7 & 8 & 1 & 8 & 1 & 0.06 & 1 & 45 & 1 & 6.25 \\
\hline 8 & 4 & -1 & 4 & -1 & 0.04 & -1 & 35 & -1 & 4.13 \\
\hline 9 & 8 & 1 & 8 & 1 & 0.04 & -1 & 35 & -1 & 8.87 \\
\hline 10 & 6 & 0 & 6 & 0 & 0.05 & 0 & 40 & 0 & 5.59 \\
\hline 11 & 10 & 2 & 6 & 0 & 0.05 & 0 & 40 & 0 & 5.38 \\
\hline 12 & 6 & 0 & 6 & 0 & 0.07 & 0 & 40 & 0 & 3.99 \\
\hline 13 & 2 & -2 & 6 & 0 & 0.05 & 0 & 40 & 0 & 4.75 \\
\hline 14 & 4 & -1 & 8 & 1 & 0.04 & -1 & 45 & 1 & 9.35 \\
\hline 15 & 8 & 1 & 4 & -1 & 0.06 & 1 & 45 & 1 & 3.01 \\
\hline 16 & 6 & 0 & 6 & 0 & 0.05 & 0 & 40 & 0 & 5.57 \\
\hline 17 & 6 & 0 & 6 & 0 & 0.05 & 0 & 40 & 0 & 5.53 \\
\hline 18 & 4 & -1 & 8 & 1 & 0.06 & 1 & 35 & -1 & 6.17 \\
\hline 19 & 6 & 0 & 6 & 0 & 0.05 & 0 & 40 & 0 & 5.55 \\
\hline 20 & 6 & 0 & 6 & 0 & 0.03 & -1 & 40 & 0 & 8.61 \\
\hline 21 & 4 & -1 & 8 & 1 & 0.06 & 1 & 45 & 1 & 6.33 \\
\hline 22 & 6 & 0 & 6 & 0 & 0.05 & 0 & 40 & 0 & 5.49 \\
\hline 23 & 4 & -1 & 4 & -1 & 0.06 & 1 & 45 & 1 & 3.07 \\
\hline 24 & 4 & -1 & 4 & -1 & 0.05 & 0 & 45 & 1 & 3.47 \\
\hline 25 & 6 & 0 & 10 & 2 & 0.05 & 0 & 40 & 0 & 9.37 \\
\hline 26 & 4 & -1 & 4 & -1 & 0.04 & -1 & 45 & 1 & 4.40 \\
\hline 27 & 6 & 0 & 2 & -2 & 0.05 & 0 & 40 & 0 & 1.59 \\
\hline 28 & 4 & -1 & 4 & -1 & 0.06 & 1 & 35 & -1 & 2.97 \\
\hline 29 & 4 & -1 & 8 & 1 & 0.04 & -1 & 35 & -1 & 9.17 \\
\hline 30 & 8 & 1 & 4 & -1 & 0.06 & 1 & 35 & -1 & 2.97 \\
\hline
\end{tabular}




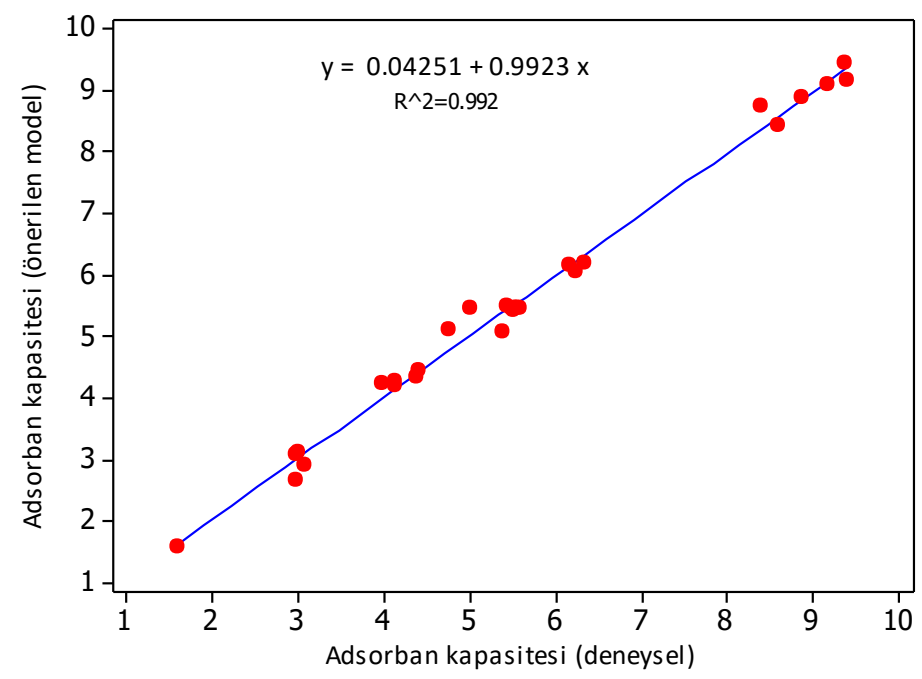

Şekil 1. Deneysel olarak elde edilen adsorban miktarının ikinci derecede etkileşimli modelden elde edilen veriler ile karşılaştırılması

Tablo 3. Yüzey yanıt yöntemi ile elde edilen etkileşimli ikinci dereceden model için ANOVA tablosu

\begin{tabular}{|c|c|c|c|c|c|}
\hline Kaynak & $\begin{array}{l}\text { Serbestlik } \\
\text { derecesi }\end{array}$ & $\begin{array}{l}\text { Kareler } \\
\text { toplamı } \\
(\mathrm{SS})\end{array}$ & $\begin{array}{l}\text { Ortalama } \\
\text { kareler } \\
\text { toplamı } \\
(\mathrm{MS})\end{array}$ & $\mathrm{F}$ & $\mathrm{P}$ \\
\hline Model & 14 & 123.392 & 8.81373 & 129.651 & $<0.00001$ \\
\hline \multicolumn{6}{|l|}{ Doğrusal } \\
\hline $\begin{array}{l}\text { X1 } \\
\text { X2 } \\
\text { X3 } \\
\text { X4 } \\
\text { İkinci derece }\end{array}$ & $\begin{array}{c}1 \\
1 \\
1 \\
1 \\
\text { imli }\end{array}$ & $\begin{array}{c}0.028 \\
94.824 \\
24.485 \\
0.017\end{array}$ & $\begin{array}{c}0.0934 \\
2.74243 \\
0.63558 \\
0.01525\end{array}$ & $\begin{array}{c}1.417 \\
40.341 \\
9.349 \\
0.224\end{array}$ & $\begin{array}{c}0.025369 \\
0.0000418 \\
0.008519 \\
0.643105\end{array}$ \\
\hline $\begin{array}{l}\text { X1X2 } \\
X 1 X 3 \\
X 1 X 4 \\
\text { X2X3 } \\
\text { X2X4 } \\
\text { X3X4 }\end{array}$ & $\begin{array}{l}1 \\
1 \\
1 \\
1 \\
1 \\
1\end{array}$ & $\begin{array}{c}0.067 \\
0.134 \\
0.041 \\
2.051 \\
0.034 \\
<0.001\end{array}$ & $\begin{array}{l}0.08546 \\
0.07747 \\
0.03988 \\
1.81367 \\
0.03930 \\
0.00056\end{array}$ & $\begin{array}{c}1.257 \\
1.140 \\
0.587 \\
26.679 \\
0.578 \\
0.008\end{array}$ & $\begin{array}{l}0.281056 \\
0.303816 \\
0.456441 \\
0.000143 \\
0.459688 \\
0.929075\end{array}$ \\
\hline \multicolumn{6}{|c|}{ İkinci dereceden etkileşimsiz } \\
\hline $\mathrm{X} 12$ & 1 & 0.408 & 0.23947 & 3.523 & 0.081534 \\
\hline $\mathrm{X} 22$ & 1 & 0.009 & 0.00288 & 0.042 & 0.839801 \\
\hline X32 & 1 & 1.293 & 1.26949 & 18.674 & 0.000704 \\
\hline $\mathrm{X} 42$ & 1 & $<0.001$ & 0.00009 & 0.001 & 0.971289 \\
\hline Hata & 14 & 0.952 & 0.06798 & & \\
\hline Model uyumsuzluğu & 9 & 0.715 & 0.07947 & 1.680 & 0.294657 \\
\hline Saf hata & 5 & 0.236 & 0.04730 & & \\
\hline Toplam & 28 & 124.344 & & & \\
\hline
\end{tabular}


Tablo 4. Adsorban olarak kullanılan Brassica Napus bitki saplarının Bakır (II) giderimindeki optimum değerleri

\begin{tabular}{ll}
\hline Değişken & Optimum değerler \\
$\mathrm{pH}$ & 5.87 \\
İlk derişim (ppm) & 7.25 \\
Adsorban miktarı $(\mathrm{g})$ & 0.03 \\
Sicaklık $\left({ }^{\circ} \mathrm{C}\right)$ & 32.63 \\
\hline
\end{tabular}

\subsection{Süreç değişkenlerinin etkisi}

Ortam pH'1 adsoprisyon sürecindeki önemli parametrelerden biridir. Ortam pH'nın adsorban yükü, iyonlaşma derecesi ve adsorban üzerindeki yüzey fonksiyonel gruplarının türleşmesi üzerinde güçlü bir etkiye sahip olduğu bilinmektedir [12,13]. Tablo 4'de bulunan $\mathrm{pH}$ değeri 5.87 iken tüm deneyler 2-10 pH aralığında yapılmıştır. Dolayısyla $\mathrm{pH}$ artı̧̧ı ile adsorpsiyon kapasitesi artmış ve belli bir maksimum değerine ulaştıktan sonra adsorpsiyon kapasitesi düşmeye başlamıştır. Literatürdeki benzer bir çalışmada [2] nar meyvesi kabuklarından elde edilen aktif karbon yardımıyla ağır metal çözeltilerden Bakır (II) giderimi, yüzey yanıt yöntemi ile incelenmiştir. Optimize edilen koşullarda optimum pH'1 5.6 olarak bulmuşlardır. Yapılan bu çalışmada ise Brassicanapus bitki sapları kullanılarak Bakır (II) gideriminde optimum $\mathrm{pH}$ değeri 5.87 bulunmuş ve literatürdeki benzer çalışmayla [2] büyük bir uyum göstermiştir. Ayrıca bu çalışmada maksimum Bakır (II) giderimi \% 89 olarak hesaplanmıştır.

Yapılan bu çalışmada Bakır (II) iyonları içeren ağır metal çözeltisi derişim aralığı 2-10 ppm seçilmiştir. Derişim, sulu faz ve katı adsorban arasındaki kütle transferi için itici gücü oluşturmaktadır. Bakır (II) giderimi 7.25 ppm derişimine kadar artış göstermiş daha sonra derişim artıkça Bakır (II) giderimi azalmıştır. $\mathrm{Bu}$ artış ve sonrasındaki azalma ağır metal çözeltisinden bakıra olan dirençteki azalış ve itici güçteki (derişim gradyeni) artıştan kaynaklanan yüksek derişimlerdeki adsorban yüzeyindeki doygunluğa bağlanabilir [2].

Bakır (II) giderimi çalışmalarında adsorban miktarı 0.030.07 gram aralığında seçilmiştir. Şekil 1 ve Tablo 3'deki varyans tablosu (ANOVA) adsorban miktarının ağır metal gideriminde güçlü etkisi göstermektedir. Genelde düşük adsorban miktarlarında $(0.03 \mathrm{mg})$ daha yüksek ağır metal giderimine ulaşılmıştır. Bunun nedeni yüksek adsorban miktarlarında adsorban yüzeyindeki aktif bağlanma noktalarının (sites) azalmasına ve adsorbanın topaklaşarak adsorban yüzey alanının azalmasıdır [15-16].

Arıtım tesislerinde kullanılmakta olan kesikli sistemler, genelde atmosfere açık ve çalışma sıcaklığı olarak $15-40{ }^{\circ} \mathrm{C}$ aralığında çalışılmaktadır. Kesikli reaktör sistemi kullanılarak Bakır (II) giderimine ilişkin yapılan bu çalışmada sıcaklık aralığı olarak $30-50{ }^{\circ} \mathrm{C}$ seçilmiştir. Ağır metal giderimi sıcaklığa bağlı olarak değişmektedir. Deneysel veriler, istatiksel analiz ve optimizasyon çalışmaları sonucunda düşük sıcaklarda $\left(32{ }^{\circ} \mathrm{C}\right)$ bakır (II) gideriminin daha yüksek olduğu bulunmuştur. Bunun nedeni adsopsiyon sürecinin ekzotermik doğasıdır [2].

\subsection{Karakterizasyon}

Adsorpsiyon öncesi ve sonrası adsorbana ait XRD pikleri Şekil 2'de gösterilmiştir. Adsorpsiyon öncesi adsorbana ait XRD pikleri incelendiğinde $22.4^{\circ}, 41.6^{\circ}$ ve $73.4^{\circ}$ görünen pikler Brassica Napus ham maddesine ait karakteristik selüloz pikleridir. Adsorpsiyon sonrası pikler incelendiğinde adsorban yüzeyinde oluşan bakır oksit $\left(\mathrm{CuO}_{2}\right)$ ve bakır nitrat $\left(\mathrm{Cu}\left(\mathrm{NO}_{3}\right)_{2}\right)$ kompleksleri XRD spektrum analizleri sonucu ortaya konulmuştur.

Adsorpsiyon öncesi ve sonrası adsorbana ait FTIR spektrumları (Şekil 3) incelendiğinde 1032 ve $3435 \mathrm{~cm}^{-1}$ dalga boyunda görülen pikler sirasıyla $\mathrm{O}-\mathrm{H}$ eğilme ve gerilme piklerine, $1248 \mathrm{~cm}^{-1}$ deki pik $\mathrm{C}=\mathrm{O}$ gerilme pikine $1429 \mathrm{~cm}^{-1}$ dalga boyundaki pik alifatik gruba bağlı C-H grubuna, $1609 \mathrm{~cm}^{-1}$ dalga boyundaki pik aromatik halkaya bağlı $\mathrm{C}=\mathrm{C}$ ve $\mathrm{C}=\mathrm{N}$ gruplarına ve $2925 \mathrm{~cm}^{-1}$ dalga boyundaki pik $\mathrm{C}-\mathrm{H}$ grubu gerilme piklerine aittir. Adsorpsiyon öncesi ve sonrası adsorbana ait FTIR spektraları büyük benzerlikler göstermektedir ve sadece pik kaymalar ve pik şiddetlerindeki değişimler görünmektedir. $\mathrm{Bu}$ değişiminin nedeni adsorpsiyon sonucu fonksiyonel grupların miktarının değişmesidir [17-18]. 


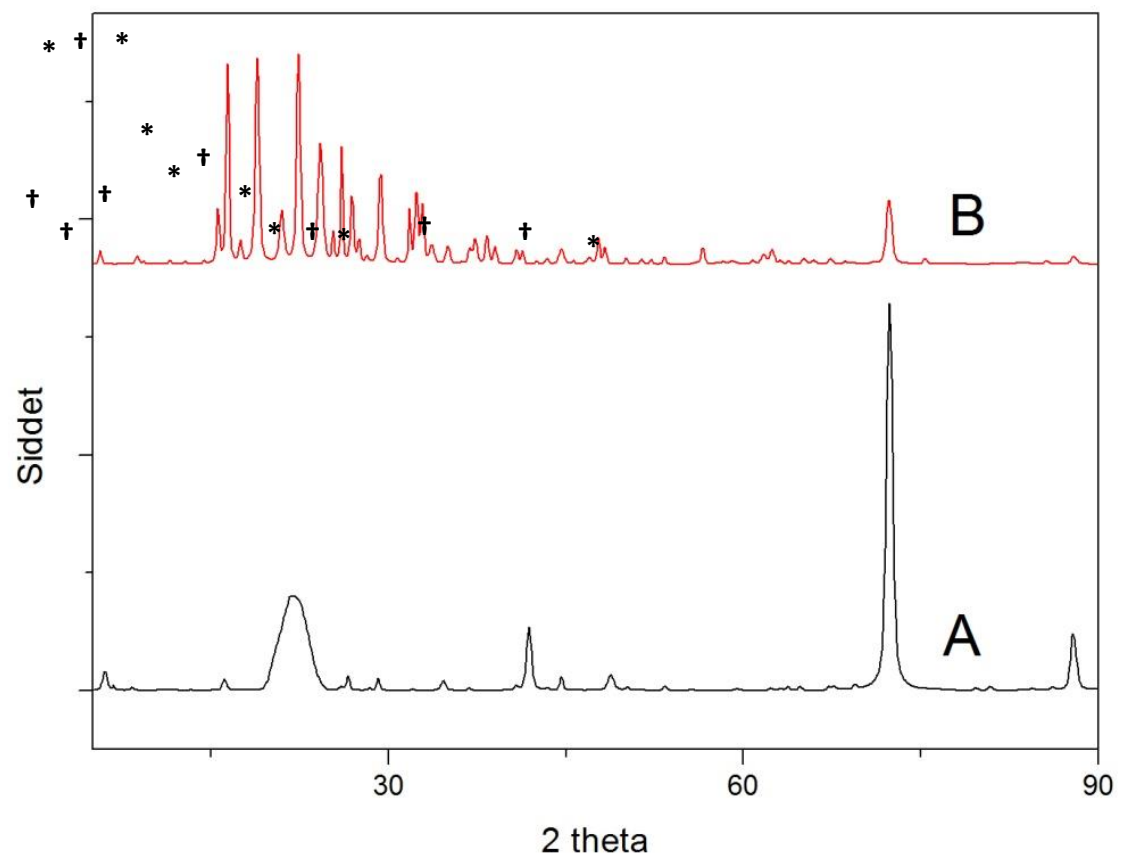

Şekil 2. Adsorbana ait adsorpsiyon öncesi (A) ve sonrası (B) XRD spektrumları (*: $\mathrm{Cu}\left(\mathrm{NO}_{3}\right)_{2} \uparrow: \mathrm{CuO}_{2}$ )

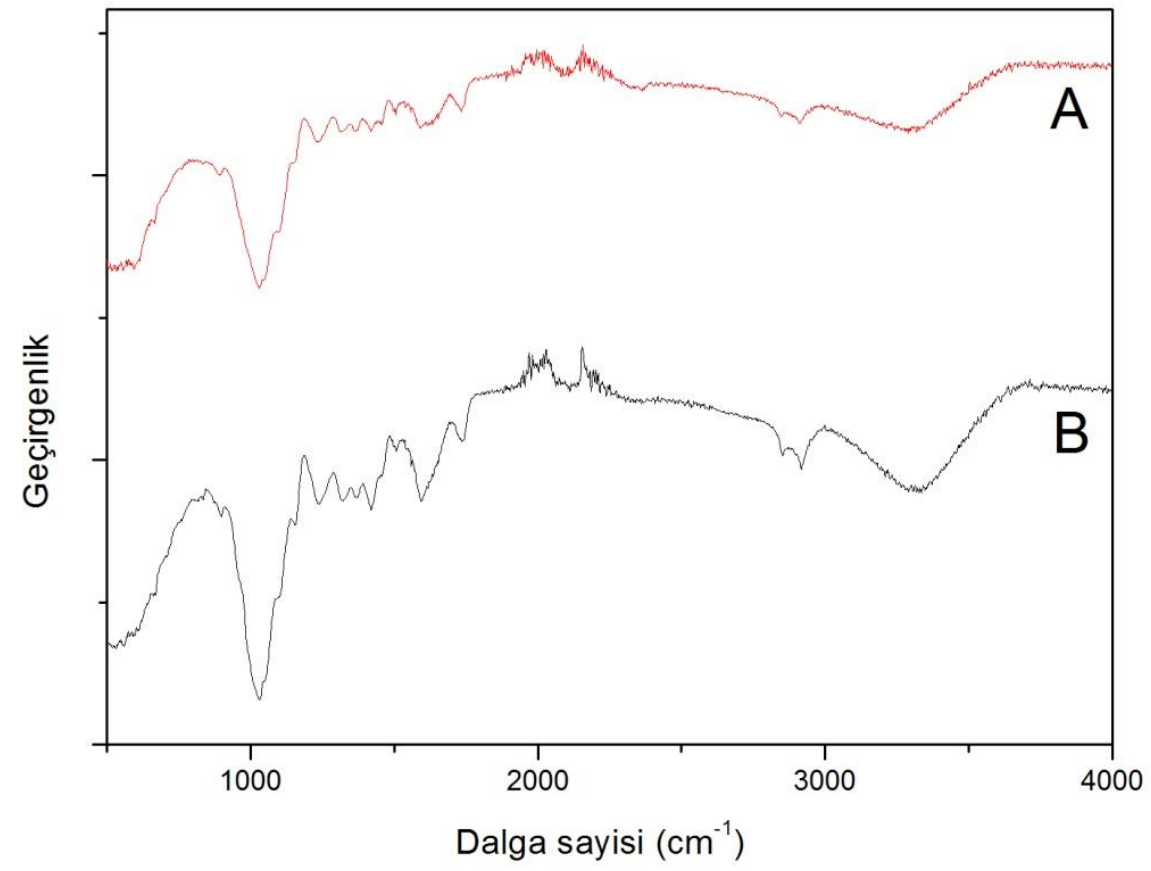

Şekil 3. Adsorbana ait adsorpsiyon öncesi (A) ve sonrası (B) FTIR spektrumları 

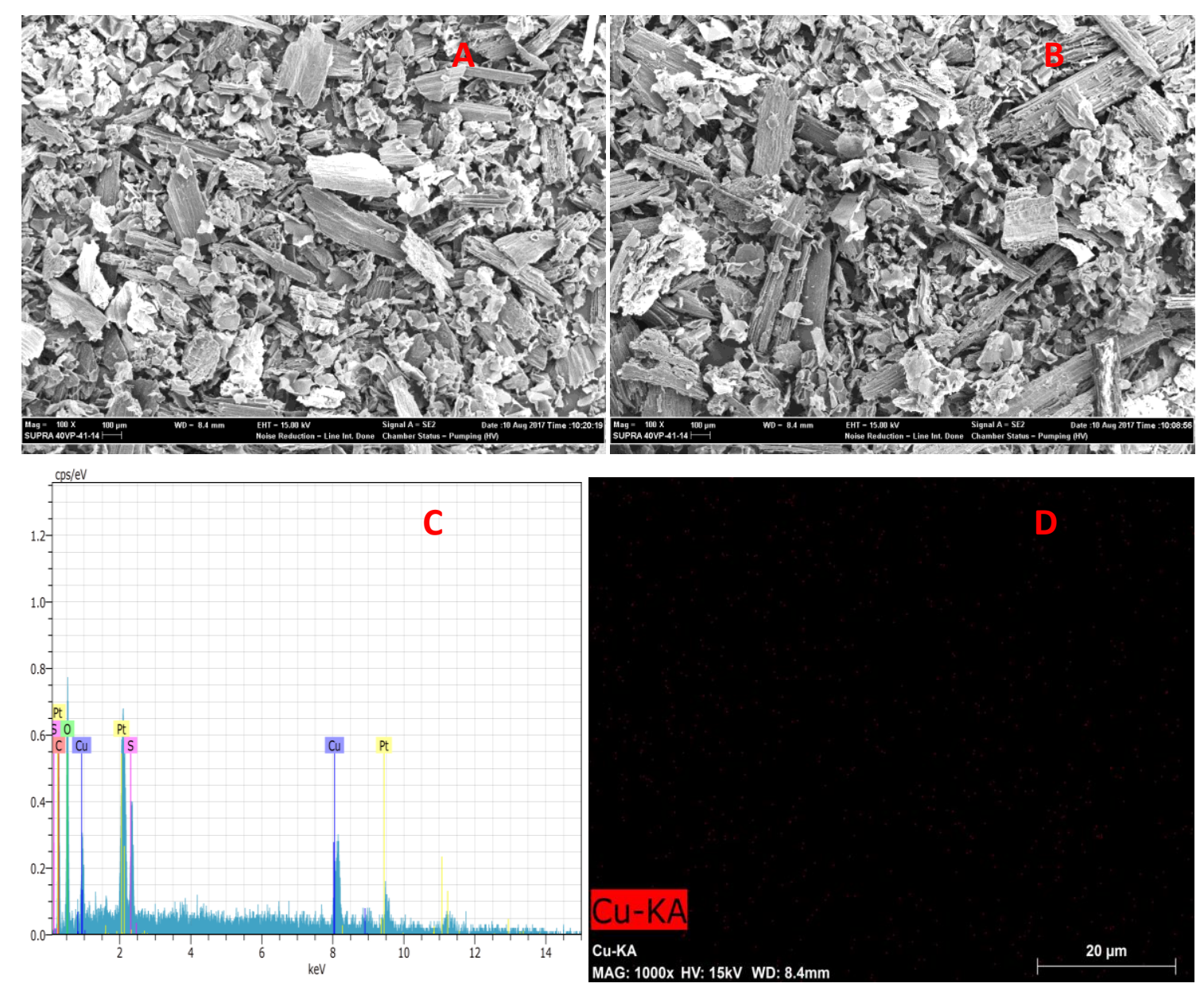

Şekil 4. Adsorbana ait SEM-EDX-Mapping görüntüleri (A: adsorpsiyon öncesi, B:adsorpsiyon sonrası ve adsorpsiyon sonras1 adsorban yüzeyi C:EDX ve D: Mapping görüntüleri)

Şekil 4 (A) ve (B)'de ağır metal giderimi öncesi ve sonrası adsorbana ait SEM görüntüleri verilmiştir. Adsorban düz ve kısmen gözenekli bir yüzey yapısına sahiptir. Bakır (II) giderimi sonrası adsorbanla yüklü yüzey daha kaba, pürüzlü ve düzensiz olduğu görünmektedir. Bunun nedeni adsorplanan bakırlı adsorban yüzeyinin ve gözeneklerinin bakır metali ile kaplanmasıdır. Bakırın adsorban yüzeyine tutulması EDX-Mapping ile de doğrulanmıştır.

\section{DEĞERLENDİRME VE SONUÇ}

Bu çalışmada Türkiye'de sadece büyük baş hayvan altılığ olarak kullanılan ve ekonomik değeri olmayan Brassica Napus bitkisi saplarının adsorban olarak kullanılabilirliği incelenmiştir.

Atık bitki saplarının Bakır (II) ağır metal giderimi deneylerinde adsorpsiyon sürecini etkileyen bağımsız değişkenler olarak pH, ağır metal derişimi, adsorban miktarı ve sıcaklık seçilmiş ve istatiksel tasarım tekniği olan Yüzey Yanıt Yöntemi ile süreç bağımsız değişkenleri optimize edilmiştir. Ağır metal giderimi deneylerinde elde edilen maksimum adsorban kapasitesi $9.37 \mathrm{mg} / \mathrm{g}$ ve elde edilen maksimum Bakır (II) giderimi \%78.34 olarak bulunmuştur.

Ayrıca süreç optimize edilerek, optimum koşullara $\mathrm{pH}$ 5.87, ilk ağır metal derişimi 7.25 ppm, adsorban miktarı $0.03 \mathrm{~g}$ ve $32.63^{\circ} \mathrm{C}^{\prime} \mathrm{de}$ ulaşılmıştır.

Deneysel ve istatiksel sonuçları Bakır (II) ağır metalini içeren sulu çözeltilerden Brassica Napus bitki saplarının kullanılmasını için uygun bir adsorban olduğunu göstermektedir. Ayrıca bu çalışma kullanılan adsorbanın diğer ağır metallerin giderilmesinde de kullanılabileceğine dair bir öngörü sağlamaktadır.

\section{KAYNAKLAR}

[1] https://www.wqa.org/Portals/0/Technical/Technical \%20Fact\%20Sheets/2015_Copper.pdf (Erişim zamanı; Mart, 29, 2018) 
[2] A. Ghaedi, M. Ghaedi, A. Vafaei, N. Iravani, M. Keshavarz, M. Rad, I. Tyagi, S. Agarwal, and V. K. Gupta, "Adsorption of copper (II) using modified activated carbon prepared from Pomegranate wood: Optimization by bee algorithm and response surface methodology," Journal of Molecular Liquids, vol. 206, pp. 195-206, 2015.

[3] H. Setiabudi, R. Jusoh, S. Suhaimi, and S. Masrur, "Adsorption of methylene blue onto oil palm (Elaeisguineensis) leaves: Process optimization, isotherm, kinetics and thermodynamic studies," Journal of the Taiwan Institute of Chemical Engineers, vol. 63, pp. 363370, 2016.

[4] H. Mahmoodian, O. Moradi, B. Shariatzadeha, T. A. Salehf, I. Tyagi, A. Maity, M. Asif, and V. K. Gupta, "Enhanced removal of methyl orange from aqueous solutions by poly HEMA-chitosan-MWCNT nanocomposite," Journal of Molecular Liquids, vol. 202, pp. 189-198, 2015.

[5] A. Hassani, L. Alidokht, A. Khataee, and S. Karaca, "Optimization of comparative removal of two structurally different basic dyes using coal as a low-cost and available adsorbent," Journal of the Taiwan Institute of Chemical Engineers, vol. 45, no. 4, pp. 1597-1607, 2014.

[6] V. Njoku, K. Foo, M. Asif, and B. Hameed, "Preparation of activated carbons from rambutan (Nepheliumlappaceum) peel by microwave-induced $\mathrm{KOH}$ activation for acid yellow 17 dye adsorption," Chemical Engineering Journal, vol. 250, pp. 198-204, 2014.

[7] N. Gupta, A. K. Kushwaha, and M. Chattopadhyaya, "Adsorption studies of cationic dyes onto Ashoka (Saraca asoca) leaf powder," Journal of the Taiwan Institute of Chemical Engineers, vol. 43, no. 4, pp. 604-613, 2012.

[8] B. Hameed, D. Mahmoud, and A. Ahmad, "Equilibrium modeling and kinetic studies on the adsorption of basic dye by a low-cost adsorbent: Coconut (Cocos nucifera) bunch waste," Journal of Hazardous Materials, vol. 158, no. 1, pp. 65-72, 2008.

[9] H. Fan, J. Yang, T. Gao, and H. Yuan, "Removal of a low-molecular basic dye (Azure Blue) from aqueous solutions by a native biomass of a newly isolated Cladosporium sp.:Kinetics, equilibrium and biosorption simulation," Journal of the Taiwan Institute of Chemical Engineers, vol. 43, no. 3, pp. 386-392, 2012.

[10] M. S. Umar, P. Jennings, and T. Urmee, "Sustainable electricity generation from oil palm biomass wastes in
Malaysia: An industry survey," Energy, vol. 67, pp. 496$505,2014$.

[11] X. Jin, M. Zheng, B. Sarkar, R. Naidu, and Z. Chen, "Characterization of bentonite modified with humic acid for the removal of $\mathrm{Cu}$ (II) and 2,4-dichlorophenol from aqueous solution," Applied Clay Science, vol. 134, pp. 8994, 2016.

[12] Tarım Bakanlığı, URL:http://www.tarim.gov.tr/sgb/Belgeler/SagMenuVeril er/BUGEM.pdf (Erişim zamanı; Mart, 29, 2018)

[13] R. Singh, R. Chadetrik, R. Kumar, K. Bishnoi, D. Bhatia, A. Kumar, N. R. Bishnoi, and N. Singh, "Biosorption optimization of lead(II), cadmium(II) and copper(II) using response surface methodology and applicability in isotherms and thermodynamics modeling," Journal of Hazardous Materials, vol. 174, no. 1-3, pp. 623-634, 2010.

[14] F. Ghorbani, H. Younesi, S. M. Ghasempouri, A. A. Zinatizadeh, M. Amini, and A. Daneshi, "Application of response surface methodology for optimization of cadmium biosorption in an aqueous solution by Saccharomy cescerevisiae," Chemical Engineering Journal, vol. 145, no. 2, pp. 267-275, 2008.

[15] M. Iqbal, N. Iqbal, I. A. Bhatti, N. Ahmad, and M. Zahid, "Response surface methodology application in optimization of cadmium adsorption by shoewaste: A good option of waste mitigation by waste," Ecological Engineering, vol. 88, pp. 265-275, 2016.

[16] Q. Manzoor, R. Nadeem, M. Iqbal, R. Saeed, and T. M. Ansari, "Organic acids pretreatment effect on Rosabourbonia phyto-biomass for removal of $\mathrm{Pb}$ (II) and $\mathrm{Cu}(\mathrm{II})$ from aqueous media," Bioresource Technology, vol. 132, pp. 446-452, 2013.

[17] Y. Wu, Z. Ming, S. Yang, Y. Fan, P. Fang, H. Sha, and L. Cha, "Adsorption of hexavalent chromium onto Bamboo Charcoal grafted by $\mathrm{Cu} 2$-N-amino propyl silane complexes: Optimization, kinetic, and isotherm studies," Journal of Industrial and Engineering Chemistry, vol. 46, pp. 222-233, 2017.

[18] S. Vilvanathanand S. Shanthakumar, "Ni (II) adsorption onto Chrysanthemum indicum: Influencing factors, isotherms, kinetics, and thermodynamics," International Journal of Phytoremediation, vol. 18, no. 10, pp. 1046-1059, 2016. 